Constructing vocational knowledge: Situations and other social sources

Stephen Billett

School of Vocational, Technology and Arts Education

Faculty of Education, Griffith University

NATHAN 4111

Australia

ph -61738755855

fax - 61738756868

email s.billett@edn.gu.edu.au

Billett S R. (1998) Situation, Social systems and learning. Journal of Education and Work 11 (3) 255-274. 


\section{Constructing vocational knowledge: Situations and other social sources}

This paper examines how social sources influence individuals' thinking, acting and construction of knowledge. Reconciling both cognitive and sociocultural constructivist perspectives, it proposes that the particular situations in which individuals engage in vocational activities should be included in frameworks which seek to explain the social genesis of knowledge and its construction by individuals. Engagement in these activities is held to lead to the transformation of individuals' knowledge through an active and reciprocal process of knowledge construction and reinforcement. This engagement, furnishes access to knowledge which is shaped by social sources comprising situational factors and socio-cultural and historical levels of development. Learning is viewed as the outcome of participation in activities within particular situations. Individuals' existing knowledge interacts with that sourced in history, culture and community during engagement in goal-directed activity. Therefore, views about relationships among social sources, thinking and learning need extending to incorporate more fully the roles that particular social circumstances play in the construction of individuals' knowledge. Consequently, the Vygotskian levels of development need to be augmented by the inclusion of the unique complexes of situational factors of communities of practice where individuals engage in goal-directed activities. However, despite this it is claimed that cognition is not situated, rather being the product of interpretative engagement with social sources which are manifested in particular situations. This view has consequences for the planning of curriculum for vocational education associated with views about curriculum goals, instruction and approach to assessment.

\section{Introduction}

This paper proposes a framework to understand further the contribution of social sources to thinking, acting and learning. In particular, it proposes that situational factors need to be considered in views about the social genesis of knowledge and in particular, vocational knowledge. The framework augments the existing development levels from Vygotskian theory (history, culture and ontogeny) with the inclusion of the contributions from the situations in which individuals' engage in vocational activities. It is held that these goal-directed activities influence cognition by engaging individuals' knowledge in activities which are a product of social sources and development. Engagement in these activities draws upon and transforms or reinforces individuals' knowledge in what is referred to as microgenetic development or moment-by-moment learning, (Rogoff 1990) thereby linking cognition with social factors. An analysis of this engagement offers a basis to understand further the relationship between social sources and cognition, as it is through individuals' engagement in these activities, securing goals and accessing guidance which contributes to the interpretative and transformative process of knowledge construction. That is, external factors (social sources) influence internal cognitive processes and outcomes (knowledge structures). This view emphasises mutuality between social circumstance and individual cognition which is consistent with current theorising (e.g. Lawrence \& Valsiner 1993; Rogoff 1995). Indeed, Valsiner (1994) refers to the coconstruction of knowledge - the reciprocal interaction between socially-sourced knowledge and individuals' existing knowledge, itself socially constructed through their life histories (ontogenies). Learning is therefore not held as being 'situated', but rather the situation provides circumstances and activities which contribute to the interpretative and negotiated process of knowledge construction. Also, 
rather than accepting the social genesis of knowledge as a single entity, it is held that levels of social sources, such as those advanced in the Vygotskian framework (Rogoff 1990, Scribner 1985) influence individuals' activities and hence their cognitive development ${ }^{1}$. Moreover, the situations in which activities occur are held to be unique, as they are shaped by a particular complex of social factors, referred to as an activity system (Engestrom 1993; Leonteyev 1981). In sum it is proposed that it is the intersection between individuals' personal history (itself a social product) and socially-determined vocational activities and goals embedded in particular circumstances (e.g., workplace, educational setting) that transforms individuals' knowledge. To advance these propositions, the paper commences by proposing a case for a relationship between learning and engaging in everyday activities such as those in particular vocational settings. Secondly, situations' contribution to thinking and acting are discussed, as are those which capture the contribution of history and culture. Thirdly, situational factors are used to augment existing levels of social sources of knowledge in order to offer a framework for considering the relationship between social system and individuals' cognition. Finally, curriculum issues associated with learning, the goals for programs, content and assessment for vocational education are advanced.

\section{Learning through engagement in activities}

A consistent view within sociocultural theory is that learning is associated with engagement in activities such as everyday vocational practice in the workplace. Rogoff and Lave (1984) go as far as proposing that activity structures cognition. That is, individuals' thinking and acting is structured by the activities they engage in, which thereby influences what is learnt and what is redeployed in other activities. Similarly, it has been proposed that, only through gaining access to real-life standpoints are individuals able to act meaningfully and purposefully because "situations might be said to co-produce knowledge through activity" (Brown, Collins \& Duguid 1989, p. 32). These authors also claim that learning is held to occur through situated activity mediated by the physical environment, the tasks and goals it furnishes, the cooperative construction of knowledge among individuals undertaking common tasks, and the culture of a specific community. What these authors are proposing is that through engagement in activities individuals learn and, moreover, that situational factors influence the knowledge that individuals construct.

The first part of this proposition is upheld by both the cognitive and sociocultural constructivist perspectives. For instance, current theorising recognises links between problem-solving and learning, supporting the view that ongoing engagement in goal-directed activities provides a basis to understanding learning. Both the sociocultural (e.g. Engestrom 1993; Rogoff, 1990; 1995) and cognitive (e.g. Anderson 1993; Shuell 1990) constructivist perspectives propose a close relationship between problem-solving and learning. Common to these perspectives is that problem-solving transforms individuals' existing

\footnotetext{
Cognitive development here includes the development of individuals' knowledge which has propositional, procedural and dispositional (values and belief) dimensions.
} 
knowledge structures. Routine problem-solving reinforces existing structures, whereas novel or nonroutine problem-solving transforms knowledge and, in doing so, extends the individuals' cognitive structures which permit performance (Groen \& Patel 1988, Stevenson 1991). The idea that problemsolving is both goal-directed and social, finds support in Leonteyev (1981, p. 46), who states that "human psychology is concerned with the activity of concrete individuals, which takes place in either a collective i.e., jointly with other people - or in a situation in which the subject deals directly with the surrounding world of objects - for example, at the potter's wheel or the writer's desk". By linking cognitive processes with human activity, Leonteyev (1981) makes a further and necessary step to include the social system which influences activity. Vocational practice exemplifies the goal-directed activity which promotes the psychological function of the practitioner (Martin \& Scribner 1991). Moreover, the situations in which vocational practice occurs provides activities, problems and options for their resolution and in doing so secures engagement between social systems and cognitive structures. This engagement is held to have cognitive consequences, as individuals' knowledge is deployed and transformed by activities, goals, solutions and judgements which are socially-derived. Furthermore, as problem-solving transforms knowledge, the kind of problem-solving activity should have particular cognitive consequences. For example, an investigation of hairdressers' construction of knowledge demonstrated that the patterning of norms and values associated with particular workplaces was evident in approaches to undertaking goaldirected activities and were also evident in the construction and organisation of the subjects' knowledge (Billett 1996b). This evidence suggests that individuals' knowledge is shaped by particular social circumstance.

However, the embeddedness of knowledge in particular circumstances has been viewed as problematic. For example, earlier views about schooling proposed that education should aim to free learners from the shackles of a particular time and place (e.g. Bartlett 1958; Bruner 1966) and develop general thinking processes, which are universally applicable, adaptable and transferable (Edwards 1991). The development of logical and rational thinking processes are favoured in this view - for example, through the use of chess and Latin. Hence, the removal of "unnecessary" distractions, is undertaken in order to develop deeper and more general thinking processes (Bruner 1966). However, there is little evidence that these approaches to instruction secured the robust and transferable knowledge desired; rather, they taught students the specific skills of chess and Latin (Glaser 1990), as learning was embedded in these activities. Likewise, it seems erroneous to claim that educational institutions such as vocational colleges and universities are somehow or can be de-contextualised and that students learn generalisable knowledge. Instead, these institutions have strong and pervasive cultures which are embedded in a particular time and place. The activities students engage in aim to secure outcomes associated with the practice of educational institutions, rather than necessarily developing forms of knowledge which are somehow inherently transferable (Raizen 1991). Therefore, because the construction of knowledge is influenced in particular ways, the knowledge 
constructed through these activities may inhibit the transfer of knowledge to other settings of a different kind, such as from the classroom to the workplace (Pea 1987; Raizen 1991; Rogoff \& Lave 1984). So, the circumstances and situations in which we engage in thinking and acting are not neutral; they are an integral part of what knowledge is constructed by individuals (Brown et al. 1989; Lave 1993; Lave \& Wenger 1991; Wertsch 1993). Hence, this view questions the separation of knowledge from the circumstances in which it is constructed and deployed. To use Scribner and Beach's (1993) analogy, engagement in activities embedded in social practice is seen as being as inseparable from learning as sodium and chlorine are from saltiness. This suggests that relationships between social sources and cognition are such that there are social dimensions to transfer which are more associated with a process of embedding and disembedding knowledge, rather than certain forms of knowledge being inherently robust and transferable. Hence, as discussed at the end of this paper, formulations of key or generic competencies for the workplace to secure transferable knowledge are probably misplaced. Rather an instructional focus on developing individuals' ability to disembed principles and practice and apply them to other circumstances is likely to assist the potential for transfer.

The consequence of learning, which is described as being situated in everyday practice, has been investigated in vocations such as navigation in Puluwat (Hutchins 1979, cited in Scribner 1984), construction work (Carraher 1986), weaving (Rogoff \& Gauvain 1984), tailoring (Lave 1977; 1990) and weaving in Zinacanteco (Childs \& Greenfield 1980). For instance, the knowledge constructed through weaving activities was found to be at least as transferable as that developed through schooling (Childs \& Greenfield 1980; Rogoff \& Gauvain 1984). Equally, Carraher's (1986) study, which compared maths used by construction supervisors with that of school students, found that the daily work of supervisors, despite their limited formal education, permitted them to develop more complex and adaptive meaning structures, associated with maths, than those possessed by school students. Studies of coalminers (Billett 1994a) and secondary process workers (Billett 1994b) also indicate that engagement in everyday goal-directed activity furnishes a basis for the development of the knowledge required for workplace performance. Hence, knowledge and skills developed through learning experiences embedded in these types of activities appear to be at least as robust as those developed through a different social setting - educational institutions.

While the aforementioned studies furnish evidence of the knowledge secured through everyday participation in vocational activities, Lave's $(1977 ; 1990)$ study of Liberian tailors' apprentices provides a rich account of how engagement in a particular vocational setting influences learning. Lave identified a pathway of activities, which the tailors' apprentices had to work through, from tasks of low accountability (e.g. undergarments or children's clothes) through to those which demand greater exactitude and higher accountability. The apprentices' activities were, therefore, a manifestation of a hierarchical social ordering 
and structuring of tailoring activities. Engagement in these activities also provided for the development of understanding about and goals for work practice. For example, apprentices' tasks commenced with the finishing off and ironing of completed garments which permitted the identification of garment pieces, their shape, and purpose and furnished the opportunity to observe the form and standard of completed garments. Learning was also mediated in more indirect ways. Mentors, comprising tailors and other apprentices, provided guidance and modelling in the workshops, and apprentices monitored their own performance against experts and other learners (Lave 1990). Guidance was also furnished by environmental clues such as completed or semi-completed garments upon which work standards could be modelled. Through its provision of access to both the process and products of the workshop, the physical environment contributes to learning. Lave (1990) notes that little in the way of explicit teaching occurs; rather participation in these activities mediates learning. So the activities are organised to provide movement from less to more accountable tasks; as well as providing access to observation, opportunities to develop models upon which to base their performance, rehearsal on more critical activities and guidance, most of which was indirect, from experts and other novices. Therefore, through engagement in this goal-directed vocational activity, guided both directly and indirectly, the apprentices constructed tailoring knowledge. In addition, and in consideration of appropriating the values and norms of tailors, apprentices lived in master tailors' houses in a street full of tailors' workshops (Lave 1977; 1990).

Similarly, in recent studies of workers' learning through participation in everyday activities in the workplace (Billett 1996c), the mediation of the social and physical environment was strongly linked to constructing the knowledge required for workplace performance. Moreover, in one of these studies it was reported that a basis for resolving workplace problems was more readily found through participating in everyday activities ("just doing it") with the direct and indirect guidance of others ("listening and observing”) than through formalised workplace instructional arrangements (e.g. text-based materials, computer-based learning technology, videos). The socially embedded and mediated approach to learning reported in these studies is analogous to the development of children's language and interpersonal skills, usually occurring in the home under the guidance of parents and caregivers between the child's first and fifth year. The learning during these years has been described as "spectacular" by Bransford, Sherwood and Hasselbring (1985), who conclude that children learn quickly with little explicit intervention and with little obvious effort (cited in Pea 1987). Three characteristics of this spectacular learning process have been identified: firstly, the learning is in context; secondly, effective mediation is provided; and, thirdly, learning is functional. These are the characteristics of individuals' engagement in activities in workplace settings.

From the foregoing, the strengths of learning, mediated through engagement in vocational activities, reside in learners' ability to participate in and observe both the process and product of the vocational practice. 
Through this mediation, it seems there is potential to develop richly associated conceptual structures and viable procedures. While undertaking vocational activities, learners are pressed into utilising and transforming their existing knowledge while engaging in goal-directed activities (problem-solving), access to direct or close (proximal) and indirect or distant (distal) sources of guidance, such as experts, peers and the physical environment assisted with this transformations in different ways. Moreover, proximal social relationships (e.g., between master and apprentice, parent and child) provide a basis for collaborative problem-solving and decision-making. Learners can also monitor their performance and access standards both explicitly and implicitly. Thus engagement in goal-directed activities presses individuals into constructing knowledge through decision-making, furnished with feedback on achieving increasingly more mature approximations of modelled tasks (Collins, Brown \& Newman 1989). There are also a range of shortcomings associated with learning through such activities which are canvassed elsewhere (Billett 1996c) including the development of inappropriate knowledge and the failure to learn important conceptual knowledge. However, the key point here is that learning is embedded in these activities and consequently what is learnt may have consequences which are desirable and undesirable to use valueladen terms.

However, it would be wrong to assume that this social sourcing of knowledge involves the transmission of knowledge shaped uniformly by these social sources. Individuals do not merely `internalise’ sociallyderived knowledge. Rather, they engage in a transformative and constructive process referred to as appropriation (Rogoff 1995) in which both the source of knowledge and learner are reciprocally transformed through individuals engagement in goal-directed activity. Valsiner (1994) emphasises mutuality between circumstances and cognition in knowledge construction, holding that rather than being a unidirectional transmission of knowledge, but one of transformation and reciprocity, characterising knowledge as being co-constructed. This mutuality suggests that cognition is not "situated", rather, it is influenced by circumstances and activities provided by the situation in which the engagement in problemsolving activity occurs.

\section{Situational factors and their contributions to thinking and acting}

The circumstances in which individuals engage in goal-directed activity have been conceptualised as communities of practice (Lave \& Wenger 1991) with the culture of practice embodying the community through its norms and values (Brown et al. 1989). These ideas have arisen from inquiry which aimed to understand the relationship between situations and cognition. Early theorising was conducted within ecological psychology which sought to understand interactions between the psychological and ecological environment - that is the cognitive and social contribution to thinking and acting. Having examined the activities of small rural communities, Barker (1968) concluded that settings cannot be dismissed as probabilistic, as they play a role in determining human behaviour. They are "seen to consist of highly 
structured, improbable arrangements of objects and events which coerce behaviour in accordance with their own dynamic patterning" (1968, p. 4). For Barker (1978), understanding how individuals' construct meaning required accounting for the ecological environment in which an individual's psychological environment is embedded. The psychological environment is viewed as "being the world as a particular person perceives it, and is otherwise affected by it"(Barker 1968, p. 4). The ecological environment is the "objective, pre-perceptual context of behaviour, the real-life settings in which people behave" (Barker 1968, p. 4). Barker (1968; 1978) held that, behaviour is shaped by settings in which individuals act, and within each setting patterns of objects and events prescribe the appropriateness of behaviour. His view of setting is therefore defined by behaviour and the uniqueness of settings' influence upon behaviour. A setting is that arena in which the behaviour is particular, and for which little of the behaviour extends into other settings. Equally, if sufficient sharing of personnel within that setting occurs, but there is limited sharing with related settings, it can be defined as a setting. Barker's behaviour settings have certain defining properties (1968, p. 78). Firstly, a standing pattern of behaviour exists, which is not a characteristic of the particular individuals involved, but is an extra-individual behavioural phenomena having unique characteristics that persist when participants change. Secondly, standing patterns of behaviour are attached to particular complexes of non-behavioural phenomena. For example, human-made parts of towns and natural features can comprise the milieu of a behaviour, independent of any individual's perception of that setting. Thirdly, the milieu is synomorphic to the behaviour - similar in structure and describing an essential feature of relationships between the behaviour and the milieu of a behaviour setting. Barker (1968) exemplified his ideas using the case of a church service, in which both pews (milieu) and the listening congregation (behaviour) face the pulpit (milieu) and the preaching pastor (behaviour). His conclusions appear to privilege the ecological over the psychological environment.

Stokols (1977), another ecological psychologist, contests the aggregation of individuals' behaviour to suggest a common patterning of responses could be predicted by a particular behaviour setting. He argues that Barker's work down-played the "mental processes through which individuals construed the potential reinforcement properties of the setting" (1977, p. 14) - the psychological environment. Barker's deterministic view of individuals' responses (behaviour) to physical settings has also been criticised by others (Engestrom 1993; Lave, Murtaugh \& de la Roche 1984) as reducing thinking and activity to a passive response to settings. Barker's intentions were to explore the relationship between the individual and the environment. His conclusions do not fully achieve this intent because he privileged the ecological environment over the psychological environment. Yet, while rejecting some details of Barker's conclusions, there is acknowledgement by his critics (Lave et al 1984) of the comprehensive evidence he furnished of settings as objective entities with influence on behaviour. 
Building on Barker's work, it is possible to propose that physical settings can be viewed as providing arenas for social practice and that social contributions are not restricted to direct and indirect interpersonal guidance, but also those provided by the physical environment. For example, Lave, et al. (1984) conclude that physical aspects of behaviour settings have durable and public properties. Supermarkets, the settings used in their investigation, appear to comprise a durable entity. They are physically, politically and socially organised "arenas" in which activity takes place (1984). For some shoppers, certain aisles do not exist, while for others they are multi-featured arenas. Lave et al. (1984) hold the relationship between the arena and setting as being the context, thereby referring to a relationship rather than an entity. This view proposes that socially-derived situations influence thinking relationally, with the nature of that influence being dependent upon the way individuals construct meaning. This supports the idea that situations mediate learning in ways that are interpretative and person-dependent, thereby emphasising mutuality between circumstances and individuals. However, person-dependency does not deny social sources. Rather, it suggests that individuals have engaged in unique combinations of social systems during their life histories which leads to quite idiosyncratic structuring of knowledge. Moreover, and as Newman, Griffin and Cole (1989) propose, through ongoing interaction within social practice individuals' knowledge associated with that social practice is likely to become similar as social interaction renders as common that knowledge.

So, to understand further the social influence on knowledge and its construction, there is a need to emphasise relations between individuals acting and the situations in which they engage in goal-directed activity. This includes the physical setting, material tools, artefacts, and the use and values of these factors and also how evolving vocational practice (e.g. tailoring) influences the activities which are embedded in particular circumstances. Hence, analyses of social practice should reflect the "relations among person, activity and situation as they are given in social practice, itself viewed as a single encompassing theoretical entity" (Lave 1993, p. 7).

The concept of community of practice, defined as a "set of relations among persons, activity and world, over time and in relation to other tangential and overlapping communities of practice" (Lave \& Wenger 1991, p. 98), provides a basis to examine the relations among social practice, thinking and learning. They propose that "a community of practice is an intrinsic condition for the existence of knowledge, not least because it provides the interpretative support necessary for making sense of its heritage" (1991, p. 98). This suggests an embeddedness of knowledge in particular circumstances, otherwise it remains dissociated from human experience. Moreover, communities of practice appear to be unique being shaped by their idiosyncratic activity systems, comprising a complex of practitioners' social factors which underpins practice (Billett 1995). The norms and values of the community comprise the culture of practice (Brown et al. 1989) thereby embodying the shaping of the community's activities by its activity system. For 
example, communities place distinct emphases on particular skills and knowledge (Goodnow 1986). Unless particular knowledge is valued in a community, individuals may be unwilling to either expend effort and/or be encouraged to secure that knowledge. Placing primacy on situational goals and values, Goodnow states that "we do not learn to solve problems - we learn what problems are considered worth solving and also what may count as an elegant solution rather than simply an acceptable solution" (1990, p. 259). This proposition supports a shift in the view of intelligence from being absolute to one which is socially-defined (Goodnow 1986, 1990) with particular circumstances (e.g. workplaces) being the circumstance where knowledge is deployed and judgements made.

Motivation and values are also associated with social systems. For instance, work interactions influence norms (Goodnow \& Warton 1991) with approaches to any shared work activity likely to include participants' expectations about each individual's contribution to, reward for and approach to the task. So, learning mediated by social practice sits within this social and task relationship, with it being determined in circumstances where individuals engage in vocational activities, for instance. It is possible to identify relations within different kinds of participation in communities, which are likely to have consequences for engagement in goal-directed activity, particularly when they are likely to be unequal (Verodonik et al. 1988). For example, individuals' response to problems are influenced by their standing in the community of practice with those who are principal participants (e.g. owners/manager), full participants (e.g. expert practitioners) and peripheral participants (e.g. novices) having access to different types of activities (Billett 1995). Moreover, those most able to determine the division of labour, for instance principal or full participants, are in a position to either inhibit or permit access to activities by peripheral participants. Access to knowledge is therefore distributed differently within communities of practice (Billett 1995). It is evident in the foregoing that aspects of social press function within communities of practice thereby signifying that this particular level in the social system needs to be accounted for in frameworks which seek to explain the influence of social factors upon cognition. A way of understanding the unique and transforming contribution of particular communities of practice is through activity systems

\section{Activity systems}

Activities can be considered as the external embodiment of community of practice. They constitute a system with its own structures, internal transformations and development - "with all its forms the individual's activity is a system in the system of social relations" (Rogoff 1990, pp. 46-47). Cole (1985) and more recently Engestrom (1993), Beach (1993) and Scribner and Beach (1993) advocate that an approach to link the social genesis of knowledge and cognition can be found within Leonteyev's (1981) work on activity systems. Leonteyev's (1981) definition of an activity system as the social system which shapes activity provides a useful basis for elaborating the nature, organisation and goals of the particular situation in which activity is undertaken. 
Engestrom (1993) advances a framework which delineates the interdependent elements which comprise activity systems of communities of practice. These elements comprise: (i) Subject - individual or subgroups whose agency is chosen as the point of view of the study; (ii) Object - raw material or problem space at which activity is directed and transformed into outcomes, with the help of tools (both internal and external); (iii) Community - multiple individuals/subgroups who share the same general objective; (iv)

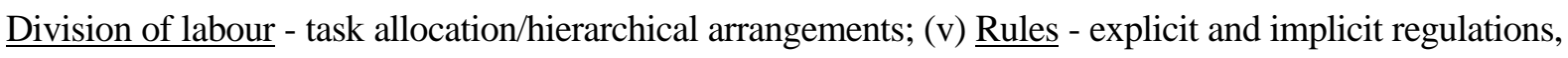
norms and conventions that constrain action and interaction; and vi) Tools - external and internal tools (mediating instruments and signs) (Engestrom 1993, pp. 67-68).

Engestrom's (1993) elements are useful in understanding the activities in workplaces as they take into account dimensions of relations, values, social context and activities which have been advanced above. However, none of the elements explicitly accommodate contributions from the physical settings, and its inclusion would benefit a framework which seeks to account for how social sources influence thinking, acting and learning. For instance, Engestrom (1993) uses his framework to analyse interactions between medical practitioners and patients. However, his elements do not account explicitly for the location of the doctor's practice within a hospital. It would seem likely that, for example, the patient-doctor interaction would be influenced by circumstances of the interaction, or the artefacts which shape such interaction, which would include the physical setting, with its likely consequence for behaviour (Rules). Just as there are rules for conduct in classrooms, workplaces and homes, equally the norms of interaction within the doctor's surgery would be salient in this analysis and is not readily accommodated for in the concept of Tools. Therefore, the inclusion of the physical setting, which is socially-derived, seems necessary to augment Engestrom's list of factors. This modification draws upon the work in ecological psychology and is supported by Martin and Scribner's (1991) who argue for a broader analysis of societal conditions, institutional settings and activity structures. Interestingly, Inhelder and Piaget (1958), who are often portrayed as being relatively unconcerned with a social basis for cognition, emphasise the physical environment and social milieu as being two factors which, together with the maturity of the nervous system, underpin the development of cognitive structures. Moreover, in any given setting, significant experiences will tend to occur in a patterned way (Scribner 1984), these experiences may be understood by including the physical setting in an analysis of activities occurring in a community of practice as perhaps Barker (1968; 1978) might have concluded.

In addition to accounting for the diversity of social influences acting on and within particular communities of practice, factors outside of the community also influence activities, namely the historical and sociocultural genesis of knowledge. From Vygotskian theory, levels of historical and cultural development are proposed which account for the social genesis of knowledge. Scribner (1985) noted that sociocultural 
practice transcends historically-evolving knowledge because cultures have different patterns of development. Equally, aspects of sociocultural practice also transcends particular communities of practice, existing across communities (e.g., workplaces) which share the same cultural practice (e.g., vocations). For example, the canonical knowledge of vocations sits outside of particular communities and, possibly, cultural practice. These historical origins are acknowledged in Vygotskian theory (Rogoff 1990, Scribner 1995) and provide both concepts and procedures for vocational activities. So the genesis of these forms of knowledge is not solely the communities in which these activities are enacted even though these are the circumstances in which they are transformed and embedded in particular ways. Therefore, it is necessary to include historical and cultural sources of knowledge as well as complexes of situational factors in frameworks which account for the social genesis of knowledge. It seems levels of history and sociocultural development and situational factors determine how activities occur in workplaces and how individuals engage in activities provided by the workplace. There is also the personal histories of individuals which have furnished the knowledge with which they will engage these social sources, albeit embedded in a particular circumstance. Having proposed that a complex of factors influence goal-directed activities within communities of practice, it is necessary to draw these factors into a framework to understand more clearly the relationship between social sources and cognition.

\section{Proposing levels of the social sourcing of knowledge}

In order to present a comprehensive view of the social genesis of knowledge and how this influences thinking, acting and learning, it is necessary to articulate more clearly how individuals' personal histories intersect with other social sources of knowledge in the interpretative co-construction of knowledge. From the Vygotskian view, four levels of social development are proposed: the phylogenetic, socio-cultural, ontogenetic and microgenetic (Rogoff 1990, Scribner 1985). Following what has been proposed above, these levels needs to be augmented by the inclusion of the community of practice to accommodate the contributions of situated factors where the historical and derived cultural knowledge is deployed and embedded in actual practice (Figure 1). Therefore, a framework which depicts the social genesis of knowledge is now advanced.

Firstly, there is the phylogenetic level of development - the evolving socio-historical source of knowledge (Vygotsky 1987; Wertsch 1985). Vygotsky (1981) has argued that humans' higher mental functions are a product of the evolving history of the species. This source furnishes procedures and goals which are likely to be common across different types of socio-cultural practice (e.g. goals for performance) and general means of securing those goals. For example, in the hairdressing study referred to above (Billett 1995) socio-historic goals associated with client servicing (e.g. client satisfaction) were identified as were the procedures associated with interacting with clients to secure those goals (e.g. finding out what is wanted, 
what is acceptable and what is not). These socio-historic forms of knowledge have evolved over time and are not the preserve of a particular vocation (sociocultural practice). For example, counting was used by Vygotsky as an example of an evolving historical process which has application across a range of human activity. However, the mode of counting and reasons for counting are not uniform, they have cultural and community purposes which result in different activities, goals and solutions to problems.

Secondly, the socio-cultural level of development embodies norms for vocational practice (e.g. medical practice, tailoring, lighthouse keeping, hairdressing). It is these norms that guide and establish expectations of vocational practitioners such as doctors, hairdressers, tailors or lighthouse keepers. These norms provide sets of concepts and procedures associated with vocational practice and how it should be performed. With hairdressing, this level provides knowledge associated with goals for and expectations of hairdressers, the techniques and practices of hairdressing (Billett 1995). These forms of knowledge provide instantiations of how socio-historic knowledge has been transformed in particular ways to accommodate the evolving sociocultural practice of hairdressing. To take another example, studies of doctors' practice (Engestrom 1993; Witzkin 1991) reveal the basis for action is characterised by the authority of medical practitioners and the relative powerlessness of patients. Equally, hairdressers negotiation with clients about their hair reveals a sociocultural practice. Such norms for interaction are likely to vary across different vocations (sociocultural practice) when dealing with a phylogenetic goal such as client servicing. Scribner (1985) originally proposed the sociocultural level of development, because Vygotsky's socio-historical source could not adequately account for the different rate and direction of the development of cultures. For example, counting has different purposes, technologies and applications across different cultures. Consider how different cultures developed different means to calculate and record meaning.

However, the sociocultural level cannot account for the deployment of sociocultural knowledge in particular circumstances because it remains disembedded from practice. That is, it is abstracted rather than embedded in particular situations. Particular communities of practice, while drawing on socio-cultural concepts and processes such as counting and language, vocational techniques or concepts will use sociocultural knowledge in particular ways dependent upon their activity systems. So as has been argued above, to account for how knowledge is transformed in particular circumstances the community of practice needs to be included in this framework.

Figure. 1 Social genesis of vocational practice

\author{
Historically derived evolving knowledge (phylogenetic) Wertsch 1985 Scribner 1985 \\ (e.g. client service or counting) \\ Guiding concepts and procedures (calculations and a number system)
}




\begin{tabular}{|c|}
\hline $\begin{array}{c}\text { Socio-cultural practice (Scribner 1985) } \\
\text { Historically derived knowledge transformed by cultural needs } \\
\text { (e.g. hairdressing, doctoring, lighthouse keeping) }\end{array}$ \\
norms, practice and expectations (particular uses and methods of counting) \\
$\begin{array}{c}\text { Community of practice (Lave \& Wenger 1991) } \\
\text { Particular socio-cultural practice shaped by a complex of circumstantial social factors (activity system) } \\
\text { norms and values which embody the community - culture of practice (Brown, et al. 1989) } \\
\text { (e.g. hairdressing salon, doctors' surgery, a particular lighthouse) } \\
\text { • } \\
\text { Microgenetic level (Rogoff 1990; Scribner 1985) } \\
\begin{array}{c}\text { Individual's construction of socially derived knowledge through routine and } \\
\text { non-routine problem-solving -which transforms and co-constructs knowledge } \\
\text { (appropriation). }\end{array} \\
\text { • } \\
\text { Ontogenetic development (Scribner 1985) } \\
\text { Individuals' personal histories } \\
\text { including participating in overlapping communities }\end{array}$ \\
\hline
\end{tabular}

Consequently, the community of practice level of development, provides a basis to understand the deployment of historically-derived sociocultural knowledge in particular circumstances. The application of sociocultural technical knowledge within different kinds of vocational practice is unlikely to be uniform, as are the social factors within the vocational practice which shape goals (Wilson 1991). Examples include a particular doctor's surgery, particular hairdressing salon or particular parental situation. For instance, medical practice will take on further variations across doctors' surgeries with the practice being shaped by demands of the particular circumstances of their application. Doctors' practices in a city hospital or surgery would be different from those in a remote Aboriginal community, for example. Equally, being a lighthouse keeper in a busy shipping channel, close to a harbour, might bring with it different demands from those of a lighthouse which signals a dangerous shoal far from major shipping lanes. Furthermore, in the hairdressing study it was evident that practice in the different salons was privileged in particular ways (techniques, work practices, values, norms) and this privileging was associated with each salons' activity systems (Billett 1995). Therefore, the transformations in the sociocultural vocational practice across different communities are embodiments of the particular situation which influences problem-solving, their solutions and, hence, what individuals learn. Communities of practice can be viewed as settings, influenced by their activity systems, which privilege situational factors as well as drawing on historically-derived sociocultural knowledge. 
The microgenetic level of development (Rogoff 1990), is the construction of knowledge through momentby-moment learning, occurring through engagement in goal-directed activities(routine and non-routine problem-solving). Individuals' existing cognitive structures intersect with those accessed through engagement in problem-solving activities which are shaped by the activity system and influenced by historical and sociocultural levels of social development. This learning is exemplified by what is described in Lave's tailoring study. The process of ongoing routine and non-routine problem-solving (microgenetic development) within the community of practice contributes to the individual tailoring apprentices' construction of knowledge which is influenced by history (clothing manufacture - customer satisfaction), culture (tailoring techniques) and community (types of garments, procedures, goals which are privileged, how labour is organised). The study of hairdressers (Billett 1996b) identified separate contributions to problem-solving by these different sources of knowledge. Problem-solutions were evident which demonstrated components of solutions which were common across all salons (socio-historic and sociocultural), specific to particular salons (communities) and had atypical factors (ontogenetic) associated with the subjects' personal history. These levels of social practice contributed to the solutions in different ways. It is through microgenetic development that individuals' interpretative and reciprocal process of the construction of knowledge occurs.

The ongoing construction of knowledge by individuals draws on, extends and organises the knowledge constructed throughout their personal histories - their ontogenetic development. Ontogenies are derived from ongoing participation in different and overlapping communities of practice (e.g. family, social relationships, professional alliances, recreational activities), each with its own norms and practices, which influence how individuals' knowledge is constructed. In the hairdressing study, most atypical responses to engagement in goal-directed activities in workplaces were associated with events in the subjects' personal histories. Hence, unique ontogenies play an important and necessary role in the interpretative construction of knowledge.

\section{Summary and implications for curriculum practice}

In sum, it has been advanced that to understand how social sources of knowledge influences thinking, acting and learning, it is necessary to include the complex of situational factors in analytical frameworks. In combination, the situational factors and levels of social sources provide a basis to understand the activities individuals engage in and from which they construct knowledge. By emphasising the mutual and interpretative relations among different sources of vocational knowledge and individuals' construction of knowledge, current views within learning theory and social cognition theory are extended. By arguing that ontogenies are themselves socially-sourced, individuals' interpretations and constructions are viewed as having a social genesis, rather than being viewed as being merely idiosyncratic and individualistic. Therefore, although this paper has delineated situational components in the social sourcing of knowledge 
which influence goal-directed activity, learning is not held to be 'situated', rather being the product of engagement in problem-solving which is influenced by social practice comprising situational factors and historical and cultural levels of development. In sum, the paper proposes a closer relationship between the social sources of knowledge and cognition and has briefly proposed what this might mean for curriculum practice within vocational education.

The significance of these views for adult and vocational education are at least fivefold. Overall, it suggests that learning is influenced by situational factors, equally expertise and transfer also have situational dimensions. This situation may help explain why knowledge may not readily transfer across settings, particularly when the focus of the sociocultural practice is different (e.g. education setting - (hairdressing college) vs hairdressing workplace -(a particular salon). Firstly, individuals' construction of knowledge appears based on their idiosyncratic personal histories. Therefore, it is unreasonable for their readiness to learn or their construction of knowledge to be uniform. Hence, processes for and the mediation of learning should be mindful of this. To expect uniform outcomes or deploy uniform instructional procedures (such the fashionable text-based flexible-delivery approach) seems unreasonable. Through engagement in particular social practice over time these differences may be addressed in the development of the canonical knowledge (sociocultural) of the vocation albeit transformed in a particular way to the needs of the community of practice. It is therefore structured in ways likely to be transferable to other vocational situations which are the same sociocultural practice (vocation) (Billett 1995). Learning isolated from opportunities to interact with others is unlikely to realise such a goal. Secondly, engagement in particular activities is likely to result in the construction of particular forms of knowledge. Workplaces and vocational educational institutions, as communities of practices are shaped by both historical and cultural developments and situational factors in the form of its activity system, are likely to be in some ways unique. That is the forms of knowledge which are required for performance, the knowledge likely to be learnt there and the particular presentation of sociocultural vocational knowledge is likely to be idiosyncratic to some degree. The expertise required for performance is unlikely to be uniform across enterprises which engage in the same sociocultural practice. Consequently, attempts at highly prescriptive curriculum intents and frameworks such as those commonly used in vocational education are unlikely to satisfactorily address the requirements of either the enterprises which are the targets of vocational education or the needs of individuals who undertake vocational education courses. Hence, curriculum processes which encompass situational factors are necessary as are instructional practices which need to both embed and abstract principles for transfer.

Thirdly, the types of activities individuals engage in will influence what learning transpires. A complication here for vocational education institutions is that their communities of practice are quite distinct from those where the vocational knowledge is targeted to be applied - workplaces. Educational 
institutions are likely to be influenced by the sociocultural practice of schooling with it goals and practices, as much as those of the particular vocation. Hence, consideration of providing opportunities for engagement in workplaces which provide authentic activities need to be considered to bridge the gap between the different social practice. This also suggests that for transfer from vocational education institutions processes of instruction need to emphasise the different ways in which the canonical knowledge of the vocation is likely to be deployed in different workplace settings. Given the emphasis on learning through ongoing problem-solving as proposed earlier, vocational educators might be also be cautioned to consider how combinations of routine and non-routine activities might best be organised to press learners into problems-solving and the reinforcement of knowledge that is learnt. That type of circumstances in which they engage in activities and also the combinations of opportunities to construct and reinforce knowledge become an important curriculum task. Fourthly, there is a need to consider the relationship between the need to address the canonical knowledge of the vocation which is furnished by the sociocultural level and the how this knowledge is transformed, privileged and deployed in particular circumstances (communities of practice). Curriculum practice within vocational education may need to emphasise curriculum intents (aims and goals) at the sociocultural level which reflect the canonical knowledge of the vocation, yet permit the detailing of those intents (objectives) to take place at the circumstances where individuals engage in goal-directed activity. Finally, rather than there being kinds of knowledge which on their own are inherently transferable (except at the most general level), learning and transfer of the learnt knowledge is associated with activities in particular circumstances and components of that knowledge being disembedded from those activities in its applications to other circumstances or situations. So rather than basing the prospect for the development of robust vocational knowledge on educational intents which claim to be transferable (key or generic competencies) it may be useful to focus on processes of instruction which aid transfer through the development of knowledge which is embedded in particular situation to make its meaning rich and then by transferred to others through abstracting from that knowledge concepts and procedures that are likely to be transferable elsewhere.

\section{References}

Anderson, J. R. (1993). Problem solving and learning. American Psychologist, 48 (1), 35-44.

Bartlett, F. C. (1958). Thinking: An experimental and social study. New York: Basic Books.

Barker, R. G. (1968). Ecological psychology: Concepts and methods for studying the environment of human behaviour. Stanford: Stanford University Press.

Barker, R. G. (1978). Habitats, environments and human behaviour. San Francisco: Jossey-Bass Publishers.

Beach, K. (1993). Becoming a bartender: The role of external memory cues in a work-directed educational activity. Applied Cognitive Psychology, 7, (3), 191-204.

Billett, S. (1996a). Situated learning: Bridging sociocultural and cognitive theorising. Learning and Instruction, 6 (3) 263-280.

Billett, S. (1996b) Constructing vocational knowledge: histories, community and ontogeny. Journal of Vocational Education and Training, 48 (2) 141-154. 
Billett, S. (1996c). Towards a model of workplace learning: the learning curriculum. Studies in Continuing Education. 18 (1) pp.43-58.

Billett, S. R. (1995). Structuring knowledge through authentic activities. Unpublished doctoral thesis. Griffith University, Brisbane.

Billett, S. (1994a). Authenticity in workplace learning settings. In J. C. Stevenson (Ed) Cognition at work: the development of vocational expertise. (pp. 36-75).Adelaide: National Centre for Vocational Education Research.

Billett, S. (1994b). Situated Learning - a workplace experience. Australian Journal of Adult and Community Education, 34 (2) 112-130.

Brown, J. S., Collins, A., \& Duguid P. (1989). Situated Cognition and the Culture of Learning. Educational Researcher, 18 (1), 32-34.

Bruner, J. S. (1966). On cognitive growth II. In J. S. Bruner, R. R. Oliver, \& P. M. Greenfield (eds), Studies in cognitive growth (pp. 30-67). New York: Wiley.

Carraher, T. N. (1986). From drawings to buildings: working with mathematical scales. International Journal of Behavioural Development, 9, 32-42.

Childs, C. P. \& Greenfield, P. M. (1980). Informal modes of learning and teaching: the case of Zinacanteco weaving. In N. Warren (ed). Advances in cross-cultural psychology, vol 2. London: Academic Press.

Collins, A., Brown J. S., \& Newman, S. E. (1989). Cognitive apprenticeship: teaching the crafts of reading, writing and mathematics. In L. B. Resnick, (ed) Knowledge, learning and instruction, essays in honour of Robert Glaser. (pp. 453-494). Hillsdale, N.J: Erlbaum \& Associates.

Cole, M. (1985). The zone of proximal development where culture and cognition create each other. In J.V. Wertsch (ed). Culture, communication and cognition: Vygotskian perspectives. (pp. 146-161). Cambridge: CUP.

Edwards, J. (1991). The direct teaching of thinking skills, in Evans G. (ed). Learning and teaching cognitive skills. Victoria, Australia: The Australian Council for Educational Research pp. 87-106

Engestrom, Y. (1993). Development studies of work as a testbench of activity theory: The case of primary care medical practice. in S. Chaiklin \& J. Lave (eds). Understanding Practice: perspectives on activity and context. (pp. 64-103). Cambridge, U.K.: Cambridge University Press.

Glaser. R. (1990). Reemergence of learning theory within instructional research. American Psychologist, 45 (1) 29-39.

Goodnow, J. J (1990). The socialisation of cognition: what's involved?. In J. W., Stigler, R. A. Shweder \& G. Herdt. (eds), Cultural Psychology. (pp. 259-86). Cambridge: Cambridge University Press.

Goodnow, J. J. (1986). Some lifelong everyday forms of intelligent behaviour: organising and reorganising. In R. J. Sternberg \& R. K. Wagner (eds), Practical intelligence - nature and origins of competence in the everyday world (pp. 143-166). Cambridge: Cambridge University Press.

Goodnow, J. J., \& Warton, P. M. (1991). The social bases of social cognition: Interactions about work and their implications. Merrill-Palmer Quarterly, 37 (1), 27-58.

Groen, G. J., \& Patel, P. (1988). The relationship between comprehension and reasoning in medical expertise. In M. T. H. Chi, R. Glaser and R. Farr, The Nature of Expertise. New York: Erlbaum.

Inhelder, B. \& Piaget, J. (1958). The growth of logical thinking - as essay on the construction of formal operational structures. (trans A. Parsons and S. Milgram) London, Routledge \& Kegan Paul.

Lave, J. (1993). The practice of learning. In S. Chaiklin \& J. Lave (eds). Understanding practice: Perspectives on activity and context (pp. 3-32). Cambridge, UK: Cambridge University Press.

Lave, J. (1990). The culture of acquisition and the practice of understanding. In J. W. Stigler, R. A. Shweder \& G. Herdt (eds). Cultural psychology (pp. 259-86). Cambridge. U.K: Cambridge University Press.

Lave, J. (1977). Tailor-made experiments and evaluating the intellectual consequences of apprenticeship training. Quarterly Newsletter of Institute for Comparative Human Development, 1, 1-3.

Lave, J., Murtaugh, M., \& de la Roche, O. (1984). The dialectic of arithmetic in grocery shopping. In B. Rogoff \& J. Lave (eds). Everyday Cognition: Its development in social context. (pp. 76-94). Cambridge: Harvard University Press. 
Lave, J., \& Wenger, E. (1991). Situated learning - legitimate peripheral participation. Cambridge: Cambridge University Press.

Lawrence, J. A. \& Valsiner, J. (1993). Conceptual roots of internalisation: From transmission to transformation. Human Development, 36, 150-167.

Leonteyev, A.N. (1981). Problems of the development of the mind. Moscow: Progress Publishers

Martin, L. M. W. \& Scribner, S. (1991). Laboratory for cognitive studies of work: A case study of the intellectual implications of a new technology. Teachers College Record, 92 (4), 582-602.

Newman, D., Griffin, P. \& Cole, M. (1989). The construction zone: Working for cognitive change in schools. Cambridge: Cambridge University Press.

Pea, R. D. (1987). Socializing the knowledge transfer problem. International Journal of Educational Research, 11 (6), 639-663.

Raizen, S. A. (1991). Learning and work: The research base. Paris OECD.

Rogoff, B. (1995). Observing sociocultural activities on three planes: participatory appropriation, guided appropriation and apprenticeship. In J. V. Wertsch, P. Del Rio \& A. Alverez (Eds.), Sociocultural studies of the mind (pp. 139-164). Cambridge: Cambridge University Press.

Rogoff, B. (1990). Apprenticeship in thinking - cognitive development in social context. New York: Oxford University Press.

Rogoff, B. \& Gauvain, M. (1984). The cognitive consequences of specific experiences - weaving versus schooling among the Navajo. Journal of Cross-Cultural Psychology, 15 (4), 453-475.

Rogoff, B., \& Lave, J. (eds). (1984). Everyday cognition: Its development in social context. Cambridge, Mass.: Harvard University Press.

Rogoff, B. \& Gauvain, M. (1984). The cognitive consequences of specific experiences - weaving versus schooling among the Navajo. Journal of Cross-Cultural Psychology, 15 (4), 453-475.

Scribner, S. (1985). Vygostky's use of history. In J. V. Wertsch (ed). Culture, communication and cognition: Vygotskian perspectives (pp. 119-145). Cambridge: Cambridge University Press

Scribner, S. (1984). Studying working intelligence. In B. Rogoff \& J. Lave (eds). Everyday cognition: Its development in social context (pp. 9-40). Cambridge, Mass: Harvard University Press.

Scribner, S., \& Beach, K. (1993). An activity theory approach to memory. Applied Cognitive Psychology, 7, 185-190.

Shuell, T. J. (1990). Phases of meaningful learning. Review of Educational Research, 60 (4), 531-547.

Stevenson, J. C. (1991). Cognitive structures for the teaching of adaptability in vocational education. In G. Evans (ed). Learning and teaching cognitive skills. (pp. 144-163). Victoria, Australia: ACER.

Stokols, D. (1977). Origins and directions of environment-behavioural research. in D. Stokols (ed). Perspectives on environment and behaviour theory, research and application. New York: Plenium Press.

Valsiner, J. (1994). Bi-directional cultural transmission and constructive sociogenesis. In W.de Graaf \& R. Maier (Eds.), Sociogenesis re-examined (pp. 101-134). New York: Springer.

Verodonik, F., Flapan, V., Schmidt, C. \& Weinstock, J. (1988). The role of power relationships in children's cognition: Its significance for research on cognitive development. Quarterly Newsletter of the Laboratory of Comparative Human Cognition (10), 80-85.

Vygotsky, L. S. (1987). Thought and Language. (ed A. Kouzulin). Massachussets: The MIT Press.

Vygotsky, L. S. (1981)

Wertsch, J. V. (1993). Voices of the mind: A socio-cultural approach to mediated action. Cambridge, Mass: Harvard University Press.

Wertsch, J. V. (ed) (1985). Culture, communication and cognition: Vygotskian perspectives. Cambridge: Cambridge University Press.

Wilson, T. P. (1991). Social structure and the sequential organisation of interaction. In D. Boden \& D. H. Zimmerman (eds). Talk and social structure (pp. 22-43). Berkeley: University of California Press.

Witzkin. H. (1991). The politics of medical encounters: how patients and doctors deal with social problems. Yale: Yale University Press. 